\title{
ANALYSIS OF ANTIOXIDANT CAPACITY AND GLUCOSE LEVEL OF BREADFRUIT LEAVES FUNCTIONAL DRINKS TREATED WITH DIFFERENT RATIO OF SWEETENERS
}

\author{
Mazarina Devi, Budi Wibowotomo, SoenarSoekopitojo. \\ Department of Industrial Technology, Faculty of Engineering. \\ Universitas Negeri Malang. \\ mazarina.devi.ft@um.ac.id, budi.wibowotomo.ft@um.ac.id, \\ soenar.soekopitojo.ft@um.ac.id
}

\begin{abstract}
Efforts to lower blood sugar levels for diabetes mellitus patients can take by consuming popular functional drinks which have been added by herbal ingredients such as breadfruit leaves. The aim of this research is to observe the effect of addition three-thaves of sweetener (aspartame, acesulfame $k$, and sorbitol) in different ratio (50\%: 25\%: 25\%, 25\%: 50\%: 25\%, 25\%: $25 \%$ : 50\%) to the antioxidant capacity and glucose level of functional drinks made from breadfruit leaves, as well as its number of calories and variety sensory tests (sour taste, sweetness and texture). The experimental design used a Completely Randomized Design with three replications. This study also employs sweetness to produce organoleptic quality data in two repetitions. All collected data were then analyzed using the ANOVA test followed by DMRT test.

Results showed that the highest antioxidant capacity was obtained by the ratio 25\%: 25\%: $50 \%$ of aspartame, acesulfame $k$, and sorbitol with an $I_{50}$ value of 64,717 ppm. Meanwhile the lowest glucose level was resulted by ratio 50\%: 25\%: $25 \%$ of aspartame, acesulfame $k$, and sorbitol in value of $25.53 \mathrm{~g} / 100 \mathrm{~g}$. The highest number of calorie was produced by ratio 25\%: 25\%: $50 \%$ of aspartame, acesulfame $k$, and sorbitol with a value of 126.44 cal. / 100gr. Whereas, the most preferred formulas of breadfruit drink formulas are found in ratio $25 \%: 25 \%: 50 \%$ of aspartame, acesulfame $k$, and sorbitol.
\end{abstract}

KEYWORDS: breadfruit leaves, functional drinks, antioxidant capacity, glucose levels.

\section{INTRODUCTION}

The number of diabetics in Indonesia is always increasing from year to year. Most environmental factors and unhealthy lifestyles, such as excessive food, fatty 
foods, lack of physical activity, and stress become the main cause of this disease. Diabetes mellitus can also appear due to heredity (Kaczmarczyk et al., 2012).

Food nutrition intake becomes an important factor in the immunity system and also essentially needed in preventing various diseases including diabetes mellitus. People with diabetes mellitus often requires special food arrangements to avoid increasing blood glucose levels. High-fibre foods such as fruits and vegetables are preferred as a source of carbohydrates because of their ability to lower blood glucose levels.

Nowadays the functional drink products such as sinom are widely consumed by Indonesian. It is much said not too safe for diabetics, due to its higher contain sugar and calories. The purpose of this study is to formulate a functional drink product made of breadfruit leaves and treated with low-calorie sweeteners such as aspartame acesulfame-k, and sorbitol. The usage of those low-calorie sweeteners in breadfruit leaves functional drink aims to reduce sugar content to be consumed safely by diabetic people.

Breadfruit plants (Artocarpusaltilis) are known in Indonesia as Suune, Amo, Hatopul, while in US popular as Breadfruit (Wardany, 2012). Several studies on the phytochemical test showed that the breadfruit leaves contain flavonoids, phenols, saponins and tannins (Baba et al., 2016). Its flavonoid compounds were also noted as strong anti-diabetes (Amarasinghe et al., 2008). Gustina and Anica (2012) reported the extract of ethanol, ethyl acetate, and butanol obtained from breadfruit leaves extract has the ability to inhibit the enzyme a-glucosidase.

In lowering the blood glucose level, people with diabetes mellitus should restrict their excessive caloric intake. Low-caloric sweeteners are medically proven safe for diabetics so that it can be used as alternative sugar-replacing. Some of such sweeteners are aspartame, acesulfame-K, and sorbitol. Aspartame is a non-calorie sweetener composed by amino acids which have purely no calorie contain.It is widely applied for low-calorie beverages/foods (Chackrewarthy et al., 2010). Acesulfame- $\mathrm{K}$ is a non-caloric artificial sweetener with a sweetness level of 200 times of sucrose (BPOM RI, 2014). The maximum usage of acesulfame-K in respective foods is $600 \mathrm{mg} / \mathrm{kg}$, while aspartame is $1000 \mathrm{mg} / \mathrm{kg}$ (Chelzea, 2011). Sorbitol is an alcoholic sugar commonly used as a substitute for sucrose for people with diabetes Mellitus has 60\% sweetness level of sucrose(Flier et al., 1987).

In the manufacture of functional drinks, the use of citric acid can be replaced by bilimbi (Averrhoa bilimbi) because it contains high natural Vitamin C of 25 $\mathrm{mg} / 100 \mathrm{~g}$ and citric acid from bilimbi is $92.6-133.8 \mathrm{meq}$ acid/100g total solid (Lima et al., 2001). From the results of phytochemical content test, Bilimbi contains oxalic compounds, saponins, phenols, flavonoids (Agustin and Putri, 2014). Saponins and flavonoids found in bilimbi can stimulate the increasing function of the pancreas in producing and releasing the insulin hormone, and also regenerate the damaged pancreatic beta cells of diabetics(Wina et al., 2005)

Synthetic aroma or flavouring is used in the manufacture of most functional drink. While in breadfruit leaves functional drink, Cinnamon (Cinnamomum cassia) is used as the natural flavour to reduce unpleasant taste of breadfruit leaves. In addition to flavouring, phytochemical compounds found in cinnamon such as 
cinnamate, cinnamaldehyde, polyphenols, and flavonoids can increase glucose transport and have a hypoglycemic effect on people with diabetes mellitus.

Hence, the purpose of this study, after the subjects are given herbal drinks, is to observe the effect of addition three-thaves of sweetener (aspartame, acesulfame $k$, and sorbitol) in different ratio (50\%: 25\%: 25\%, 25\%: 50\%: $25 \%, 25 \%: 25 \%$ : $50 \%$ ) to the antioxidant capacity and glucose level of functional drinks made from breadfruit leaves, as well as its number of calories and variety sensory tests (sour taste, sweetness and texture).

\section{METHODOLOGY}

The research is an experimental research using a Complete Randomized Design (RAL) as experimental design. The main treatment was ratio in percentage of aspartame, acesulfame-K, and sorbitol applied in the manufacture of functional drinks. The detailed combination ratios are of 50\%:25\%:25\%, 25\%:50\%:25\%, and 25\%:25\%:50\%, respectively to the aspartame, acesulfame-K, and sorbitol. Each treatment was repeated twice.

The raw materials used in the manufacturing process are breadfruit leaves, carrageenan, aspartame, acesulfame-K and sorbitol, bilimbi, and cinnamon.

Table1. Experimental Design

\begin{tabular}{|c|c|c|c|}
\hline & \multicolumn{3}{|c|}{ Treatment } \\
\hline Replication & S1 & S2 & S3 \\
\hline R1 & S1R1 & S2R1 & S3P1 \\
R2 & S1R2 & S2R2 & S3P2 \\
\hline
\end{tabular}

Description:

Treatment: Ratio of aspartame, acesulfame k, dan sorbitol (S)

1 :functional drink with ratio $50 \%: 25 \%: 25 \%$

2 :functional drink with ratio $25 \%: 50 \%: 25 \%$

3 :functional drink with ratio $25 \%: 25 \%: 50 \%$

Replication(R)

1 :first replication

2 :second replication

\subsection{Observation}


Observation was carried out on breadfruit leaves functional drink products by analyzing the glucose content, antioxidant capacity, and calories content.

\section{RESULTS AND DISCUSSION}

\subsection{Glucose Content}

The average glucose content of the breadfruit leaves functional drink can be seen in Table 2 .

Table 2. The average of glucose content on breadfruit leaves functional drink $(\mathrm{g} / \mathbf{1 0 0 g})$

\begin{tabular}{|c|c|c|c|}
\hline \multirow{2}{*}{$\begin{array}{c}\text { Sweetener ratios } \\
\text { (aspartame, acesulfam-K and } \\
\text { sorbitol) }\end{array}$} & $\mathbf{1}$ & \multirow{2}{*}{ Replication } & \\
\cline { 2 - 3 } & & $\mathbf{2}$ & \\
\hline $50 \%: 25 \%: 25 \%$ & 25,23 & 25,83 & 25,53 \\
\hline $25 \%: 50 \%: 25 \%$ & 29,21 & 29,66 & 29,43 \\
\hline $25 \%: 25 \%: 50 \%$ & 31,42 & 31,79 & 31,60 \\
\hline
\end{tabular}

Table 3. ANOVA Test Result of Glucose content on breadfruit leaves functional drink.

\begin{tabular}{|l|r|r|r|r|r|}
\hline & Sum square & \multicolumn{1}{|c|}{ Df } & Mean squares & \multicolumn{1}{c|}{ F } & \multicolumn{1}{c|}{ Sig. } \\
\hline Inter-group & 37,909 & 2 & 18,955 & 162,607 &, 001 \\
\hline Intra-group &, 350 & 3 &, 117 & & \\
\hline Total & 38,259 & 5 & & & \\
\hline
\end{tabular}

The results of ANOVA testing glucose content showed that ratio of $50 \%: 25 \%: 25 \%$ was significantly different with the ratio of $25 \%: 50 \%: 25 \%$, the ratio of $25 \%: 50 \%: 25 \%$ was significantly different with the $25 \%: 25 \%$ $\%: 50 \%$, and ratio of $25 \%: 25 \%: 50 \%$ differed significantly with the ratio of $50 \%: 25 \%: 25 \%$.

\subsection{Antioxidant Capacity}


The average antioxidant capacity of the breadfruit leaves functional drink can be seen in Table 4.

Table 4. Average antioxidant capacity on breadfruit leaves functional drink (IC50, ppm)

\begin{tabular}{|c|c|c|c|}
\hline \multirow{2}{*}{$\begin{array}{c}\text { Sweetener ratio } \\
\text { (aspartame, acesulfame-K and } \\
\text { sorbitol) }\end{array}$} & $\mathbf{1}$ & \multirow{2}{*}{ Average } \\
\cline { 2 - 3 } & & $\mathbf{2}$ & \\
\hline $50 \%: 25 \%: 25 \%$ & 92,625 & 91,328 & 91,976 \\
\hline $25 \%: 50 \%: 25 \%$ & 72,446 & 71,434 & 71,94 \\
\hline $25 \%: 25 \%: 50 \%$ & 64,919 & 64,515 & 64,717 \\
\hline
\end{tabular}

Table 5. ANOVA test results of antioxidant capacity on breadfruit leaves functional drink.

\begin{tabular}{|l|c|c|c|c|c|}
\hline & $\begin{array}{c}\text { Sum } \\
\text { squares }\end{array}$ & Df & Mean squares & F & Sig. \\
\hline Inter-group & 797,806 & 2 & 398,903 & 833,915 &, 000 \\
\hline Intra-group & 1,435 & 3 &, 478 & & \\
\hline Total & 799,241 & 5 & & & \\
\hline
\end{tabular}

The results of ANOVA test in antioxidant capacity showed that ratio of 50\%:25\%:25\% was significantly different with $25 \%: 50 \%: 25 \%$, ratio of 25\%:50\%:25\% was significantly different with $25 \%: 25 \%: 50 \%$, and ratio of 25\%:25\%:50\% differed significantly with 50\%:25\%:25\%.

\subsection{Calorie Content}

The average calorie content of breadfruit leaves functional drinks can be seen in Table 6 .

Table 6. Average calorie content of breadfruit leaves functional drink (cal/100g)

\begin{tabular}{|c|c|c|c|}
\hline Sweetener ratio & \multicolumn{2}{|c|}{ Repetition } & \multirow{2}{*}{ Average } \\
\cline { 2 - 3 } $\begin{array}{c}\text { (aspartame, acesulfame-K and } \\
\text { sorbitol) }\end{array}$ & 1 & 2 & \\
\hline
\end{tabular}




\begin{tabular}{|c|c|c|c|}
\hline $50 \%: 25 \%: 25 \%$ & 100,94 & 103,32 & 102,13 \\
\hline $25 \%: 50 \%: 25 \%$ & 116,86 & 118,67 & 117,76 \\
\hline $25 \%: 25 \%: 50 \%$ & 125,70 & 127,19 & 126,44 \\
\hline
\end{tabular}

Table 7. ANOVA test result of Energy amount on breadfruit leaves functional drink

\begin{tabular}{|l|r|r|r|r|r|}
\hline & \multicolumn{1}{|c|}{$\begin{array}{c}\text { Sum } \\
\text { squares }\end{array}$} & \multicolumn{1}{|c|}{ Df } & Mean squares & \multicolumn{1}{c|}{ F } & \multicolumn{1}{|c|}{ Sig. } \\
\hline $\begin{array}{l}\text { Inter- } \\
\text { group }\end{array}$ & 607,343 & 2 & 303,672 & 163,256 &, 001 \\
\hline $\begin{array}{l}\text { Intra- } \\
\text { group }\end{array}$ & 5,580 & 3 & 1,860 & & \\
\hline Total & 612,924 & 5 & & & \\
\hline
\end{tabular}

The results of ANOVA test in calorie content showed that ratio of 50\%:25\%:25\% was significantly different with the ratio $25 \%: 50 \%: 25 \%$, the ratio of 25\%:50\%:25\% was significantly different with the $25 \%: 25 \% \%: 50 \%$, and the ratio of $25 \%: 25 \%: 50 \%$ was significantly different with of $50 \%: 25 \%: 25 \%$.

\subsection{Sensory Test of Taste}

The average result of the sensory test of taste on breadfruit leaves functional drink can be seen in Figure 1.



Ratio Aspartam, Asesulfam K, and Sorbitol

Figure 1: Average Scores of Sensory test of taste on breadfruit leaves the functional drink 
The Figure 1showed that ratio of 50\%:25\%:25\% has 4,15 score of sensory taste, ratio of $25 \%: 50 \%: 25 \%$ has 3,87 score of sensory taste, mean while ratio of $25 \%: 25 \%: 50 \%$ has 4,33 score of sensory taste ratio which was no different significantly with ratio of $50 \%: 25 \%: 25 \%$.

\subsection{Sensory Test of Aroma}

The average of sensory test result of aroma on breadfruit leaves functional drink can be seen in Figure 2.

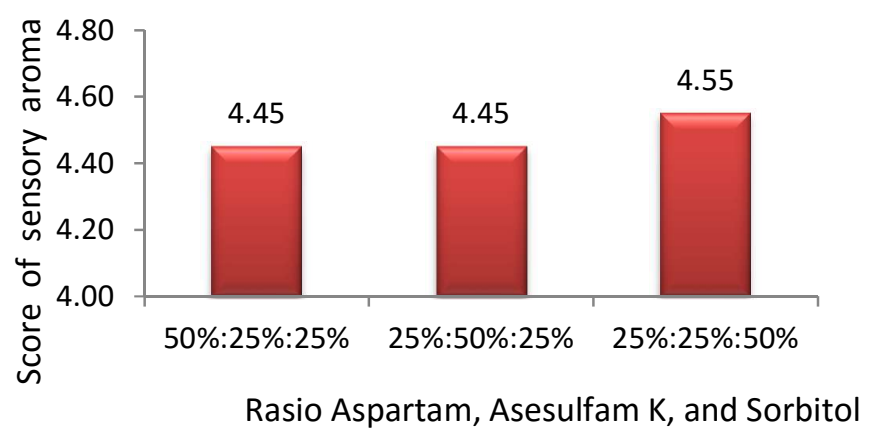

Figure 2: Average score of sensory test of aroma on breadfruit leaves functional drink

The Figure 2 above showed that score of sensory aroma of 4,45 resulted from both ratio of 50\%:25\%:25\% and $25 \%: 50 \%: 25 \%$, whereas the ratio of 25\%:25\%:50\% has 4,55 score of sensory aroma. There was no significant difference in sensory of aroma on breadfruit leaves functional drink with different ratio of aspartame, acesulfame-K and sorbitol.

\subsection{Sensory Test of Color}

The average of sensory test results of colour on breadfruit leaves functional drink can be seen in Figure 3.

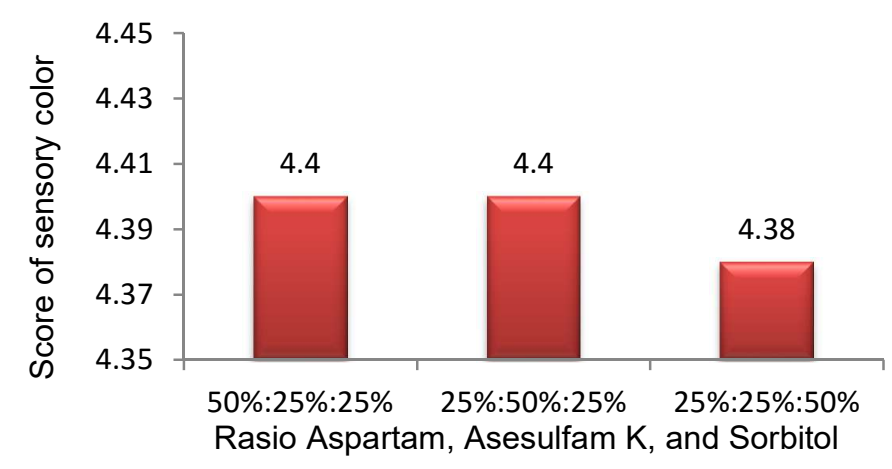




\section{Figure 3: Average score of sensory test of colour on breadfruit leaves functional drink}

The Figure 3 above showed that score of sensory colour of 4,4 resulted from both ratio of 50\%:25\%:25\% and $25 \%: 50 \%: 25 \%$, whereas the ratio of 25\%:25\%:50\% has 4,38 score of sensory colour. There was no significant difference in sensory of colour on breadfruit leaves functional drink with different ratio of aspartame, acesulfame-K and sorbitol.

\subsection{Sensory Test of Texture}

The average of sensory test results of texture on breadfruit leaves functional drink can be seen in Figure 4.

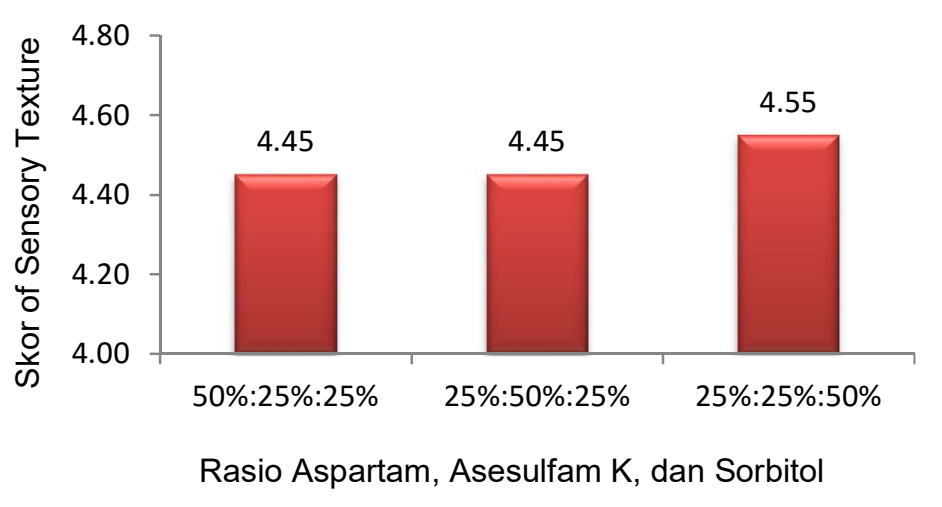

\section{Figure 4: Average score of sensory test of texture on} breadfruit leaves functional drink

The Figure 4 above showed that score of sensory texture of 4,45 resulted from both ratio of 50\%:25\%:25\% and 25\%:50\%:25\%, whereas the ratio of $25 \%: 25 \%: 50 \%$ has 4,55 score of sensory texture. There was no significant difference in sensory of texture on breadfruit leaves functional drink with different ratio of aspartame, acesulfame-K and sorbitol.

\subsection{Sensory Quality Test of Sour Taste}

The average result of sensory quality test of sour taste on breadfruit leaves functional drink can be seen in Figure 5 


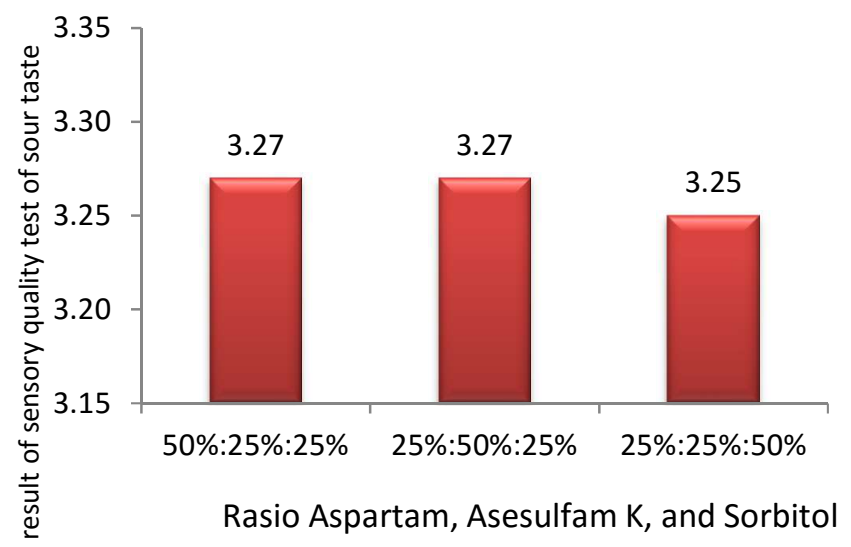

\section{Figure 5: Average result of sensory quality test of sour taste on breadfruit leaves functional drink}

The Figure 5 above showed that sensory quality score of sour taste of 3,27 resulted from both ratio of 50\%:25\%:25\% and 25\%:50\%:25\%, whereas the ratio of 25\%:25\%:50\% has 3,25 sensory quality score of sour taste. There was no significant difference in sensory quality of sour taste on breadfruit leaves functional drink with different ratio of aspartame, acesulfame-K and sorbitol.

\subsection{Sensory Quality Test of Sweet Taste}

The average result of sensory quality test of sweet taste on breadfruit leaves functional drink can be seen in Figure 6.

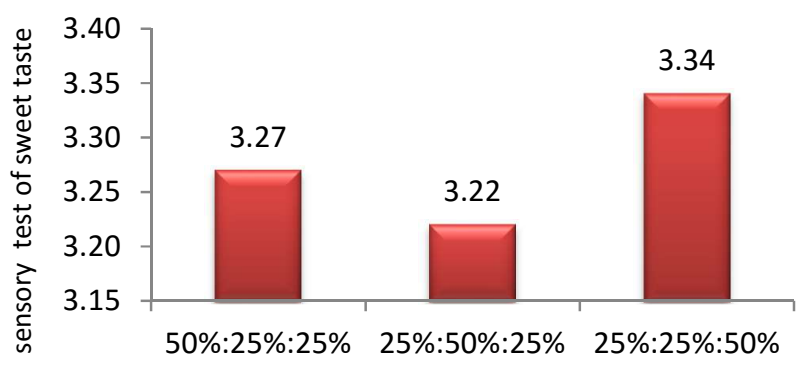

Rasio Aspartam, Asesulfam K, and Sorbitol

Figure 6: Average result of sensory quality test of sweet taste on breadfruit leaves functional drink

The Figure 6 showed that ratio of 50\%:25\%:25\% has 3,27 sensory quality score of sweet taste, ratio of 25\%:50\%:25\% has 3,22 sensory quality score of sweet 
taste, meanwhileratio of $25 \%: 25 \%: 50 \%$ has 3,34 sensory quality score of sweet taste.

\subsection{Sensory Quality Test of Texture}

The average result of sensory quality test of texture on breadfruit leaves functional drink can be seen in Figure 7.

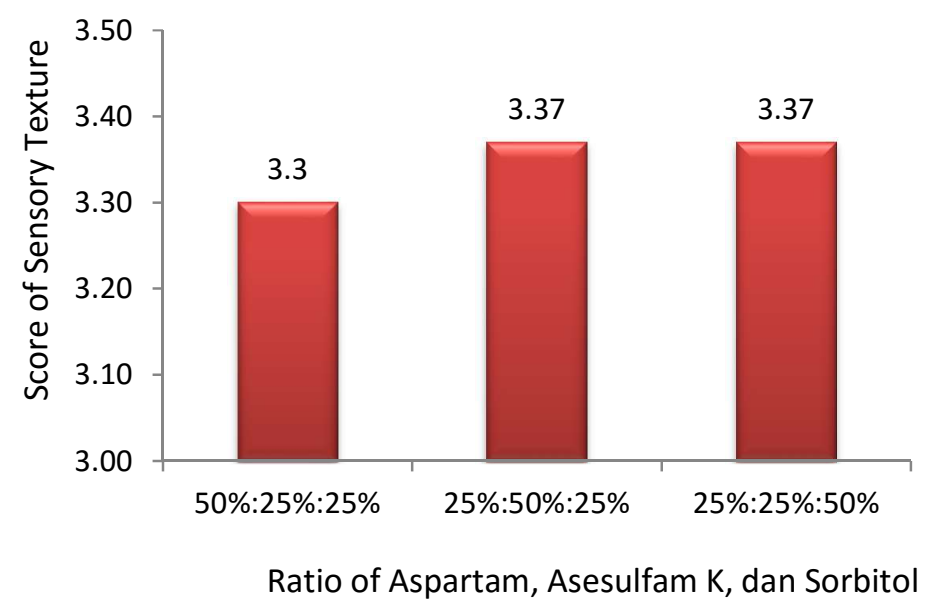

\section{Figure 7. Average result of sensory quality test of texture on breadfruit leaves functional drink}

The Figure 7 showed that ratio of 50\%:25\%:25\% has 3,30 sensory quality score of texture, whereas ratio of 25\%:50\%:25\% and 25\%:25\%:50\% has similar 3,37 sensory quality score of texture.

The observation showed that glucose content in breadfruit leaves functional drink was affected significantly by different treatment of aspartame, acesulfame-K and sorbitol ratio. The highest glucose content in ratio of $25 \%: 25 \%: 50 \%$ was probably caused by the high percentage of sorbitol compared with aspartame and acesulfame-K. Caballero (2003)said that sorbitol is a natural sweetener which is not classified as reducing sugar because it is made of glucose from the breakdown of tuber starch through high-pressure hydrogenation which produces alcoholic sugar.

Sorbitol production using high-pressure hydrogenation process aims to convert aldehyde groups of glucose into hydroxyl groups that turn glucose into sorbitol or glucitol which is an alcoholic sugar (Sigman-Grant and Morita, 2003). Bauditz et al., (2008) reported that the absorption of alcoholic sugars by the body has slower rate. Hence, it will reduce the glucose incremental and insulin response which related to glucose digestion process. Therefore, sorbitol becomes an alternative sweetener for people with diabetes mellitus. 
The antioxidant capacity of the breadfruit leaves functional drink is also affected significantly by different treatment of aspartame, acesulfame-K, and sorbitol ratios. The highest antioxidant capacity resulted by ratio of 25\%:25\%:50\% was more probably obtained by the use of more sorbitol percentage than aspartame and acesulfame-K. Sorbitol is a raw material of synthetic Vitamin C. Vitamin C can be synthesized from sorbitol because it has a similar molecular chain link. Sorbitol molecular has chain link of C6H1406 while vitamin C is structured of C6H806. Vitamin $\mathrm{C}$ is derived from sorbitol by oxidization process into sorbose and then commercially synthesized with the catalyst of acetobacter bacteria to produce synthetic vitamin C (Sayuti and Yenrina, 2015).

Beside of sorbitol effect, the antioxidant capacity of breadfruit leaves functional drink was also influenced by the use of several additional ingredients such as breadfruit leaves material, carageenan and bilimbi fruit extract. Breadfruit leaves contain saponins, flavonoids and tannins, in which the highest content of flavonoids found in old breadfruit leaves, which is equal to $100.68 \mathrm{mg} / \mathrm{g}$, while young breadfruit leaves contain $87.03 \mathrm{mg} / \mathrm{g}$, and fallen old leaves of breadfruit is $42.89 \mathrm{mg} / \mathrm{g}$ (Fajaryanti et. Al., 2016).

The higher percentage of sorbitol compared than aspartame and acesulfame$\mathrm{K}$ results in higher calories of 25\%:25\%:50\% ratio. Sorbitol has $2.6 \mathrm{cal} / \mathrm{gr}$ while sucrose contains $4 \mathrm{cal} / \mathrm{gr}$ (Peters and Lock, 1958). Aspartame and acesulfame-K have no calories content. This ratio produces breadfruit leaves functional drink with a fresh sweet and sour taste. Sweet taste may come from the combination of aspartame, acesulfame-K, and sorbitol while the sour taste was derived from the use of bilimbi fruit extract.

By overall sensory test, breadfruit leaves functional drink can be accepted by panellists. The highest average value of sweet taste was obtained from 25\%:25\%:50\% ratio. All panellists were perceived by a similar sweet taste like sugar. This is due to higher percentage of sorbitol than aspartame and acesulfame$\mathrm{K}$, resulted the relatively similar sweetness level as sugar. Whereas the breadfruit leaves functional drink with 25\%:50\%:25\% ratio has slightly sour sweet taste.By the sensory test of taste, breadfruit leaves functional drink with $25 \%: 25 \%: 50 \%$ ratio was most preferred, which has sugar-like sweet taste. Its average score was 4.3.

Breadfruit leaves functional drink has a distinctive aroma produced by the addition of bilimbi extract and cinnamon. This addition is intended to reduce the unpleasant aroma produced by the leaves of breadfruit. Based on the preference data resulted by 35 panellists through 2 repetitions, it was found that the aroma of the breadfruit leaves functional drink can be accepted by the panellist with its preference level is preferred.

The result of preference test of aroma on breadfruit leaves functional drink with different aspartame, acesulfame-K, and sorbitol ratios have average value of 4.454.55. The highest value of 4.55 was obtained from $25 \%: 25 \%: 50 \%$ ratio while 50\%:25\%:25\% and 25\%:50\%:25\% ratio has average value of 4.45 .

Breadfruit leaves functional drink has a clear green colour due to the natural colour of breadfruit leaves. Although it has a clear green colour, the results of preference test indicated that breadfruit leaves functional drink produced can be 
received by the panellists with preference level of preferred and average preference value between 4.38-4.4. Breadfruit leaves functional drink with different ratios has the same preference level because of the same breadfruit leaves extract composition. The composition of breadfruit leaves extract used on each ratio is 100 $\mathrm{ml}$.

Overall, the taste of breadfruit leaves functional drink is acceptable by all panellists. The highest average taste value of 3.27 was obtained from 50\%:25\%:25\% and 25\%:50\%:25\% ratios which have a sour taste while the lowest average taste value of 3.25 was obtained from $25 \%: 25 \%: 50 \%$ ratio which has a fairly sour taste. This such taste is probably due to higher percentage of sorbitol than aspartame and acesulfame-K. The relatively higher amount of sorbitol used in functional drink will produce a functional drink with lower sour taste (Sari et al., 2016). Sorbitol has similar characteristics as fructose that binds $\mathrm{H}+$ ion which will reduce the total amount of acid on the ingredients.

\section{CONCLUSION}

The difference of aspartame ratio, acesulfame-K, and sorbitol in breadfruit leaves functional drink has significant effect on glucose level, dietary fibre, antioxidant capacity, amount of energy, physical properties of colour, and sensory properties of taste. The lowest glucose level of $25.53 \mathrm{~g} / 100 \mathrm{~g}$ obtained from $50 \%: 25 \%: 25 \%$ ratio. The highest antioxidant capacity of $64.717 \mathrm{ppm}$ obtained from 25\%:25\%:50\% ratio. The highest energy amount of $126.44 \mathrm{cal} / 100 \mathrm{~g}$ obtained from 25\%:25\%:50\% ratio. The highest sensory properties of taste obtained from 25\%:25\%:50\% ratio with a score of 4.3 (like). The highest sensory properties of aroma obtained from 25\%:25\%:50\% ratio with a score of 4.55 (like). The highest sensory properties of colour obtained from 50\%:25\%:25\% and $25 \%: 50 \%: 25 \%$ ratio with a score of 4.4 (like). The highest sensory properties of texture obtained from 25\%:25\%:50\% ratio with a score of 4.55 (like). The highest sensory quality of sour taste obtained from 50\%:25\%:25\% and 25\%:50\%:25\% with a score of 3.27 (acid). The highest sensory quality of sweet taste obtained from 25\%:25\%:50\% ratio with a score of 3.34 (sweet). The highest sensory quality texture obtained from 25\%:25\%:50\% and 25\%:50\%:25\% ratio with a score of 3.37 (crushed).

Based on the results of research on glucose level, total dietary fibre, antioxidant capacity, calorie count, physical properties of colour, and organoleptic properties of breadfruit leaves functional drink, can be suggested as follows, It is necessary to conduct some research in the difference of phytochemical content between the young and old breadfruit leaves, the use of stabilizers on breadfruit leaves functional drink product, and preservation level of breadfruit leaves functional drink.

\section{ACKNOWLEDGEMENTS}


Authors thank Universitas Negeri Malang for funding this research by PNBP Scheme.

\section{REFERENCES}

Amarasinghe, N.R., Jayasinghe, Lalith., Hara, Nilupa., Fujimoto, Yoshinori. (2008). Chemical constituents of the fruits of Artocarpus altilis. Biochem. Syst. Ecol. 36, 323-325. https://doi.org/10.1016/j.bse.2007.09.007

Baba, Syigeyuki, Chan, Hung, Kezuka, Mio, Inoue, Tomomi, Chan, Eric (2016). Artocarpus altilis and Pandanus tectorius: Two Important Fruits of Oceania with Medicinal Values. Emir. J. Food Agric. 28, 531. https://doi.org/10.9755/ejfa.2016-02-207

BPOM (2014) Decree of the head of food and drug supervisory agency of Republic of Indonesia No. 4 years 2014 about the maximum limit the use of additional material for the food special market operation of sweetening

Bauditz, Juergen, Norman, Kristina, Biering, Henrick, Lochs, Herbert, Pirlich, Matthias(2008). Severe weight loss caused by chewing gum. BMJ 336, 9697. https://doi.org/10.1136/bmj.39280.657350.BE

Caballero, Benjamin (Ed.) (200)3. Encyclopedia of food sciences and nutrition. Academic Press, Amsterdam.

Chackrewarthy, S., Thabrew, Mi, Weerasuriya, M.Kb, Jayasekera, S. (2010). Evaluation of the hypoglycemic and hypolipidemic effects of an ethylacetate fraction of Artocarpus heterophyllus (jak) leaves in streptozotocin-induced diabetic rats. Pharmacogn. Mag. 6, 186. https://doi.org/10.4103/09731296.66933

Fajaryanti, Nurrochmad A, Fakhrudin N. (2016). Evaluation of Antihyperlipidemic Activity and Total Flavonoid Content of Artocarpus altilis Leaves Extracts. International Journal of Pharmaceutical and Clinical Research 2016; 8(5)Suppl: 461-465

Flier, J.S., Underhill, L.H., Greene, D.A., Lattimer, S.A., Sima, A.A.F. (1987). Sorbitol, Phosphoinositides, and Sodium-Potassium-ATPase in the Pathogenesis of Diabetic Complications. N. Engl. J. Med. 316, 599-606. https://doi.org/10.1056/NEJM198703053161007

Kaczmarczyk, Melisa.M., Miller, MichaelJ., Freund, Gregory G. (2012). The health benefits of dietary fibre: Beyond the usual suspects of type 2 diabetes mellitus, cardiovascular disease and colon cancer. Metabolism 61, 10581066. https://doi.org/10.1016/j.metabol.2012.01.017

Lima, Vera Lucia Arroxela.G.D., MéLo, Enayde.D.A., Santos Lima, Lueci.D. (2001). Physicochemical Characteristics Of Bilimbi (Averrhoa bilimbi L.). Rev. Bras. Frutic. 23, 421-423. https://doi.org/10.1590/S010029452001000200045 
Peters, R., Lock, R.H. (1958). Laxative Effect of Sorbitol. BMJ 2, 677-678. https://doi.org/10.1136/bmj.2.5097.677

Sari, Derta., Ginting, Sentosa., dan Lubis, Zulkifli (2016). The influence of comparison sorbitol concentration sorbitol with purple sweet potato and karagenan concentration to the quality of candy jelly.Journal of food technology vol 4 ( 3 ). The faculty agricultural, University of Sumatera Utara

Sayuti, Kesuma dan Yenrina, Rina (2015). Natural Antioxidant and synthetic. Padang: Andalas University Press

Sigman-Grant, M., Morita, J. (2003). Defining and interpreting intakes of sugars. Am. J. Clin. Nutr. 78, 815S-826S. https://doi.org/10.1093/ajcn/78.4.815S

Wardany, Ketty. 2012.Efficacy of breadfruit.Yogyakarta: Rapha Publishing.

Wina, E., Muetzel, Stefan, Becker, Klaus(2005). The Impact of Saponins or Saponin-Containing Plant Materials on Ruminant ProductionA Review. J. Agric. Food Chem. 53, 8093-8105. https://doi.org/10.1021/jf048053d 